\title{
Teachers' Achievement Goals and Teaching Practices: A Standardized Lesson Diary Approach
}

\author{
Martin Daumiller \\ University of Augsburg \\ Michaela S. Fasching \\ Oliver Dickhäuser \\ University of Vienna \\ University of Mannheim \\ Markus Dresel \\ University of Augsburg
}

\begin{abstract}
Motivation plays a central role in faculty members' professional lives - with achievement goals having been found to have important links with their burnout/engagement and performance. However, the few studies investigating these links were cross-sectional and considered only one of the two equally important work do- mains of faculty members. In the present research, we analyze the temporal relationships between achievement goals and burnout/engagement as well as performance and investigate domain specificity of goal pursuit by considering goals for teaching and for research. We conducted a longitudinal study (4 measurement points across two years) including 681 German faculty members. Multivariate Latent Change Score modeling attested that in both domains, mastery-approach goals were positively related to subsequent development of performance, while performance was also positively related to subsequent development of mastery goals, creating a double positive loop. Performance goals and work-avoidance goals were differentially associated with performance in both domains, indicating that the effects of goals can be bound to different contextual features. For overall burnout/ engagement, our results implied that primarily research goals mattered for its development (with performance- avoidance and work-avoidance goals being risk factors), while high burnout levels were associated with sub- sequent reduction of adaptive mastery-approach goals in both domains. This highlights the relevance of achievement goals for burnout/engagement and performance of faculty and illuminates their complex temporal dynamics that can also meaningfully inform achievement goal research in other contexts.
\end{abstract}

Keywords: Achievement goals; Goal orientations; Teacher motivation; Instruction; Teaching

(C) 2023, Elsevier Inc. The official citation for this manuscript is: Daumiller, M., Fasching, M., Dickhäuser, O. \& Dresel, M. (2023). Teachers' achievement goals and teaching practices: A standardized lesson diary approach. Teaching and Teacher Education, 127, 104079. Advanced online publication. https://doi.org/10.1016/j.tate.2023.104079. This paper is not the copy of record and may not exactly replicate the final, authoritative version of the article. The final article will be available, upon publication, via its DOI.

\section{Introduction}

Mr. Perfoy employs a fixed lesson regime in which he regularly emphasizes competition in his classrooms

Correspondence concerning this article should be addressed to Martin Daumiller, Department of Psychology, University of Augsburg,

Universitätsstr. 10, 86135 Augsburg, Germany;

Martin.Daumiller@phil.uni-augsburg.de.

We have no known conflicts of interest to disclose.

This work was supported by the German Ministry for Education and Research under Grant 01HJ0902 (Markus Dresel) and 01HJ0901 (Oliver Dickhäuser). We thank Sebastian Nitsche for his scientific work within the respective research project and Judith Hellwig for her contribution to data collection. to incite top performance through students outperforming each other. His colleague, Ms. Leary, encourages students to take an active role in their learning and strives to provide them with maximum autonomy and collaborative learning methods. Why do teachers differ so strongly in their use of teaching practices that vary in instilling lasting and high-quality learning motivation in students? Besides differences in knowledge and socialization, educational researchers argue that this might be due to the personal motivations that teachers hold for their jobs (see Han \& Yin, 2016; Lauermann $\&$ Butler, 2021). In fact, this is a key premise of the achievement goal approach, a prominent motivation 
theory (Butler, 2007, 2014). Following this approach, different personal goals are distinguished that teachers pursue to different extents. These goals have been found to be differentially associated with teachers' experiences and cognitions. Past research has also investigated linkages with teaching practices; however, most studies have considered teaching practices on a superordinate level (distinguishing between two global teaching foci: mastery and performance practices) and-given that other sources of information, such as student or external observer reports, are often effortful and less ecological-have relied on cross-sectional assessments of teachers' trait use of teaching practices (see overview by Daumiller et al., 2022). Such research approaches can be severely affected by retrospective and response biases (e.g., Trull \& Ebner-Priemer, 2013) and do not allow for a differentiated view on teaching practices and their variability across different lessons. To overcome these limitations, we propose a standardized diary approach (focusing on multiple, specific lessons and asking for teachers' ratings immediately after their lessons) and investigate how different goals give rise to the use of ten theoretically grounded teaching practices central to motivating lessons.

\subsection{Achievement Goals for Teaching}

Schools are considered achievement arenas both for students and teachers who pursue different personal goals for themselves therein (Butler, 2007). The achievement goal approach distinguishes different types of goals that can be pursued to varying degrees, each with its own set of cognitive, behavioral, and affective consequences (Elliot \& Hulleman, 2017). This approach has been successfully used to describe the achievement motivation of primary, secondary, and higher education teachers (Butler, 2007; Daumiller et al., 2019; Papaioannou \& Christodoulidis, 2007).

Goals are cognitive representations of desired results of actions (Pintrich, 2000a). They characterize the direction and meaning of individual behaviors, influencing how individuals think, behave, and emotionally respond to different situations (Schutz et al., 2001). In their daily practice, teachers generally pursue multiple goals directed at different targets (such as their students, their pedagogical activities, or themselves; e.g., Hagger \& Malmberg, 2011; Niikko \& Ugaste, 2011), centered around different topics (e.g., well-being, curriculum development, further learning, career development; see Mansfield \& Beltman, 2014), and situated on different levels of hierarchy (ranging from general life goals to specific goals in a current teaching situation; see e.g., Jang, 2019; Janke \& Dickhäuser, 2019). Different theories focus on different sets and conceptualizations of these goals to better understand human experiences and behaviors. In the present paper, we use the achievement goal approach (Ames \& Ames, 1984; Dweck, 1984; Nicholls, 1984; see Elliot \& Hulleman, 2017) as a conceptual framework to analyze instructional consequences of teachers' goals. This approach describes motivational differences between individuals by focusing on their self-directed goals regarding the purpose of achievement related behavior (see Ames, 1992), characterizing the different ways teachers conceptualize success (Butler, 2012) and personal competence (Mascret et al., 2017).

Aligning with common theorizing on the different types of achievement goals, the following goals are typically distinguished in teachers (Butler, 2007): learning goals (teachers' aim to develop own competencies, knowledge, and skills), performance approach goals (teachers' aim to demonstrate superior performance relative to others), performance avoidance goals (teachers' aim to avoid demonstrating inferior performance relative to others), and work avoidance goals (teachers' aim to get through the day with little effort). Teachers differ in the extent to which they pursue these different goals, with goal pursuit having been found to be partially stable as well as variable across time (see Daumiller et al., 2023; Praetorius et al., 2014). ${ }^{1}$ These different orientations towards these goals shape perceptions and interpretations of achievement situations and possibilities for action - affecting teachers' learning, experiences, and behaviors. Teachers' learning goals have been found to be positively associated with favorable attitudes, help seeking, self-efficacy, job satisfaction, and professional development; conversely, teachers' performance avoidance and work avoidance goals have been found to be positively associated with maladaptive attitudes, low self-efficacy, professional stress experiences, and number of sick days (e.g., Cho \& Shim, 2013; Daumiller et al., 2021, 2022; Daniels et al., 2013; Gorozidis \& Papaioannou, 2014; Janke et al., 2019; Nitsche et al., 2011, 2013a,b; Runhaar et al., 2010; Skaalvik \& Skaalvik, 2017). These studies indicated a less clear pattern of effects regarding teachers' performance approach goals, which have been found to be associated with both positive and negative processes

\footnotetext{
${ }^{1}$ Against this background, we use the term "achievement goals" instead of "goal orientations", as the latter might imply a primarily dispositional character (Praetorius et al., 2014).
} 
(similar to findings with students, Elliot \& Hulleman, 2017).

Beyond this, teachers' achievement goals have also been posited to influence what teachers do in class (Butler, 2007; Butler \& Shibaz, 2008). In a recent overview of the linkages between teachers' achievement goals and teaching behaviors, Daumiller et al. (2022) found that most studies rely on cross-sectional, self-reported trait use of teaching practices (cf. Butler, 2012; Butler \& Shibaz, 2008, 2014; Daumiller et al., 2016, 2022; Schiefele \& Shaffner, 2015). Typically, these studies have distinguished between a mastery- and a performance-oriented teaching focus-emphasizing student learning and improvement, or competition and social comparison, respectively - that was assessed through self-reports by teachers on a superordinate level (e.g., Butler, 2012; Daniels, 2015; Mascret et al., 2017; Retelsdorf et al., 2010; Shim et al., 2013; Wang et al., 2017). This means that these studies did not ask teachers about specific instructional practices (such as cognitively stimulating students, as an aspect of mastery-oriented teaching; or using negative public feedback as an aspect of performance-oriented teaching) but rather about general self-reports of these two broad categories of teachers' approaches to instruction (frequently relying on the Patterns of Adaptive Learning Scales; PALS, Midgley et al., 2000). In contrast, studies assessing specific teaching practices are rare and only consider few and select practices (e.g., social support: Butler, 2012; cognitive stimulation: Butler \& Shibaz, 2014; expectation, structure, autonomy support, relatedness: George \& Richardson, 2019; information transmission and conceptual change strategies: Han et al., 2015; promotion of surface learning and of comprehension learning: Retelsdorf \& Günther, 2011). Overall, many of the studies on this topic have identified positive associations between learning goals and mastery-based practices and between performance avoidance goals and performance-based practices. In addition, negative links between mastery goals and performance practices and between performance goals and mastery practices have also been identified, painting an uncertain pattern of results that warrants further research.

Taken together, these studies provide evidence to support the premise that teachers' achievement goals matter for their teaching practices. However, the pattern of results is not always consistent across studies, which might be due to the studies having focused on superordinate strategies and trait reports that can easily be biased by self-serving tendencies or teaching ideals (Kunter \& Baumert, 2006). Besides being more easily assessable by teachers, considering a broad set of specific teaching practices is necessary to understand how exactly achievement goals give rise to higher or lower teaching quality and different outcomes.

\subsection{Investigating Specific Teaching Practices as Consequences of Teachers' Achievement Goals}

Teaching is the main task of teachers, and the different teaching practices that teachers carry out are closely tied to educational quality. Such practices encompass teachers' behaviors in the classroom that are intentional, outcome-oriented, and more or less planned. As such, they can be expected to be linked to teachers' achievement goals: Different teaching practices form different behavioral possibilities with varying functionality for reaching one's self-related goals (e.g., trying to make lessons particularly interesting can also help teachers to learn something new themselves, thus contributing to their own learning goals). At the same time, teachers' achievement goals give rise to different definitions of success and different views on competence - and these different definitions should also underly their assumptions of which teaching practices serve to instill success and competencies in students (e.g., if a teacher strongly values performance, they should be more likely use teaching practices directed at fostering competition between students).

While multiple frameworks exist to describe teaching quality and to distinguish different sets of teaching practices (Praetorius et al., 2020), we take a motivational approach in the present work to derive the relevant teaching practices that we investigate. This approach focuses on differences in what teachers do in their classrooms, which motivate students to different extents (Ames, 1992; Lüftenegger et al., 2014, 2017). As described before, prior achievement goal research often considered mastery- and performance-based approaches to instruction on a broad level, that is, without distinguishing the different teaching practices underlying these broad categories. However, research has pointed to the merits of comprehensively considering multiple teaching practices based on such frameworks to better understand effects of teachers' goals on teaching outcomes (Daumiller et al., 2022). One well-established approach to distinguish the relevant teaching practices underlying mastery- and performance-based teaching constitutes the consideration of teaching practices that give rise to mastery and performance goal structures in class, as highlighted in the TARGET model (Ames, 1992; Lüftenegger et al. 2014, 2017). Benning et al. (2019) revised this model to contain four, more distinct and additionally enriched dimensions (content, evaluation and recognition, autonomy, and 
social dimensions of teaching; see Figure S1 in the supplementary materials). Considering the content of these dimensions serves to derive the individual teaching practices (that we are interested in the present work) that can give rise to high-quality motivational climates in form of mastery climates (i.e., mastery-based teaching practices) as opposed to performance climates in class (i.e., performance-based teaching practices; see Janke et al., 2022):

(1) The content dimension refers to the extent to which lessons focus on understanding learning content (regarding the different tasks and quality of engaged time). Teachers can achieve this through clear instruction, cognitive stimulation, individualization of lessons, and promoting interestingness. Doing so, sufficient time for learning and individual progress of students should be ensured. Among these aspects, increasing cognitive stimulation and interestingness are particularly well documented to foster students' learning motivation and performance (Ames, 1992; Kunter et al., 2013; Nicholls, 1989).

(2) The evaluation and recognition dimension expresses the extent to which teachers create an evaluation climate that values competence development through providing feedback on students' individual learning progress and supporting effort-based attributions. An important, opposite aspect to this end is public negative teacher feedback that is frequently used and creates a strong performance climate as opposed to a mastery climate in class.

(3) The autonomy dimension pertains to how often students are given opportunities to make meaningful choices and to take personal responsibility for their learning process. Through autonomy support and structuring of lessons, students can be supported to independently engage with the subject matter, leading to more pleasant experiences regarding the pursuit of learning goals in class (Benita et al., 2014).

(4) Finally, the social dimension refers to students receiving social support during the learning process, which helps them to feel less alone and less frustrated when learning (Patrick et al. 2011). Social support can be provided either directly through teachers' behaviors, or indirectly through the creation of a positive climate among students. Collaborative instead of competitive forms of teaching and learning are assumed to be especially suitable to facilitate such a class climate. Furthermore, heterogeneous instead of homogenous groups should be formed to avoid labelling poor-performing students as outsiders (Ross \& Harrison 2006).

\subsection{Assessment of Teaching Practices Through Lesson Diaries}

Given that teaching practices are mostly conscious, they can be assessed through self-reports (Pintrich, $2000 \mathrm{~b}$ ). While other sources of information, such as reports from students or external observers, provide many advantages, using them is often more effortful and ecologically challenging, leading to studies frequently relying on an assessment of trait use of teaching practices (see Daumiller et al., 2022). This approach can, however, be affected by self-esteem-serving tendencies and retrospective and response biases (Goetz et al., 2015; Trull \& Ebner-Priemer, 2013). Problems with global self-reports can particularly be heightened due to common method biases (when teachers report all constructs within the same questionnaire), resulting in general recommendations of measuring independent and dependent variables with different assessment methods (Podsakoff et al., 2003).

Especially for the assessment of teaching practices by teachers, a standardized diary approach appears very suitable (Martschinke \& Kammermeyer, 2003). A standardized lesson diary is a highly structured set of items with closed response scales with which a teacher reports on their specific teaching practices in the actual lessons (Rausch, 2014). Such a diary should increase ecological validity due to fewer recall errors occurring the closer the reports are to the event (see Schmitz \& Wiese, 2006). By reporting their behaviors immediately after a lesson, teachers should be able to reflect more accurately on teaching practices that occurred within the respective lesson, while the focus on a specific classroom additionally reduces a possible over-estimation of the quality of one's teaching. Opposed to approaches with students or observers - that are frequently limited in terms of the number of measurement points, items, and constructs to be assessed due to practical considerations (acceptance by participants, effort) - such an approach further allows for easy modelling of variability in teachers' behaviors (which is especially relevant as certain teaching practices require multiple lessons to be adequately observed; Praetorius et al., 2014) and for differentiated assessments of multiple teaching behaviors. While typically being more time consuming and associated with higher participant drop-out than cross-sectional questionnaires (Rausch, 2014), diaries allow for more detailed, valid, and reliable insights into what is going on in the classroom. Diaries have already been successfully used to capture and investigate teachers' emotions (Frenzel \& Götz, 2007; Goetz et al., 2015), and first studies have begun using such an approach for assessing classroom actions 
(Martschinke \& Kammermeyer, 2003). Therefore, we consider such an approach very useful for assessing and providing detailed insights into teaching practices, as well as for overcoming limitations of past research regarding how teachers' goals matter for teaching practices.

\subsection{The Present Research}

In the present research, we address an important assumption of teacher motivation research and two key limitations of prior research. Specifically, we consider theoretically grounded teaching practices central to motivating lessons and use a standardized lesson diary approach for assessing them. Our main research question focuses on the linkages between achievement goals and these teaching practices. Based on theorizing into the different motivational systems spanned up by the goals and the empirical evidence presented before, we hypothesized that (1) learning goals are positively associated with teaching practices that are mastery-based, and negatively associated with performance-based teaching practices, (2) performance goals are positively associated with performance-based practices, and (3) performance avoidance and work avoidance goals are positively associated with performance-based and negatively associated with mastery-based practices. Given that both achievement goals and teaching practices might partly differ between teachers depending on their gender and teaching experience (see supplementary materials), it is warranted to include gender and teaching experience as control variables when studying the effects of teachers' goals on instruction (Authors, 2020; Nitsche et al., 2013b). While we expect effects of goals to be robust depending on gender and experience (Nitsche et al., 2013b), we specifically test this assumption to yield more thorough insights into how goals are linked to teaching practices.

\section{Method}

To answer our research questions, we asked German high school teachers to fill out a questionnaire about their achievement goals and, over the course of five subsequent lessons, also standardized diaries concerning their specific teaching practices. $^{2}$

\subsection{Procedure}

After receiving approval from the respective ministry, German Gymnasium (upper track of German secondary schools, comparable to grammar school) teachers who taught Mathematics or German (as a mother tongue) in the $8^{\text {th }}$ grade were recruited using multiple incentives (non-monetary gifts, individual feedback based on the collected data). We specifically focused on Mathematics and German as these are principal subjects in all German schools. First, teachers completed a questionnaire assessing achievement goals and biographical data. Next, teachers reflected on five consecutive lessons using a standardized lesson diary directly after each lesson. We provided them with instructions on how to fill out the lesson diary, including guidelines for unforeseen circumstances (e.g., when classes got cancelled, teachers were instructed to continue with the next lesson).

\subsection{Sample}

A total of 196 high schools in Bavaria, a federal state in Germany, were contacted; of which 58 (29.6\%) schools with 177 teachers were willing to participate. Of those interested teachers, a total of 146 questionnaires $(82.5 \%)$ and 136 classroom diaries $(76.8 \%)$ were returned. From 12 teachers $(8.22 \%)$ we only received the initial questionnaire but not the lesson diary; two teachers $(1.47 \%)$ only returned the diary but not the questionnaire. As our inclusion criteria required both the questionnaire and the diary, the final sample consisted of 134 teachers with 670 lesson diaries. Of those, 71 were women $(53.0 \%)$ and 63 men $(47.0 \%)$, with an average age of $38.5(S D=11.0)$ years. Seventy-four (55.2\%) taught mathematics and 60 (44.8\%) taught German (L1). They had one to 36 years of teaching experience $(M=10.4, S D=10.3)$.

\subsection{Measures}

\section{Baseline Questionnaire: Achievement Goals for Teaching}

We used the questionnaire by Nitsche et al. (2011) to measure teachers' achievement goals. Following the item stem "In my vocation, ...", learning goals were assessed with 9 items (e.g., "I aspire to improve my pedagogical knowledge and my competences"; Cronbach $\alpha=.80$ ), performance approach and performance avoidance goals were each measured with 12 items combining appearance and normative aspects within each item (e.g., "I aspire my colleagues to realize that I teach better than other teachers", "I aspire my students not to believe I would master my job less sufficient than other teachers", $\alpha=.90-.95$ ), and work avoidance goals were measured with 3 items (e.g., "I aspire to get through the day with little effort"; $\alpha=.81$ ) on a 5-point Likert scale ranging from 1 (strongly disagree) to 5 (strongly agree).

\section{Standardized Lesson Diary: Teaching Practices}

Teachers reported on their practices over the course of five subsequent lessons. Following Ames (1992) and Benning et al. (2019), we assessed ten teaching practices referring to the content (interestingness, cognitive 
stimulation, individualization), evaluation (public negative feedback), autonomy (autonomy support, structuring), and social (collaboration, heterogeneous grouping, homogeneous grouping, competition) dimensions of teaching. We specifically focused on aspects that should be clearly assessable by teachers and selected both mastery- (i.e., interestingness, cognitive stimulation, individualization, autonomy support, structuring, collaboration, heterogeneous grouping) as well as performance-based aspects (i.e., public negative feedback, homogeneous grouping, competition). Whenever possible, we relied on established scales from large-scale surveys that we slightly adapted to the diary approach. Some scales were originally formulated from the student perspective and adapted to the teacher perspective following the work of Retelsdorf et al. (2010). Specifically, we assessed interestingness with a total of six items, using five items from Ditton (2010) supplemented by an additional item from Baumert et al. (2008) to also include the relevance of the topic for everyday life. Cognitive stimulation was assessed with four items (Ramm et al., 2006). Individualization was measured with a scale from Baumert et al. (2008) that we shortened to three items. We used the scale from Dresel et al. (2009) to measure public negative feedback with three items. Further, we compiled a total of six items from existing scales (Black \& Deci, 2000; Frey et al., 2009; Kunter et al., 2007; Rakoczy etal., 2005) to assess autonomy support. Structuring was measured with two items from Baumert et al. (2008). Following Baumert et al. (2008), we developed four items measuring the extent to which teachers fostered collaboration among students. Heterogeneous grouping and homogenous grouping of students was assessed based on Helmke et al. (2007) with two items each. Finally, we assessed the extent to which teachers promoted competition in the classroom with five items analogously to the collaboration measure. We provide further details about the scales, their reliabilities, and sample items in Table 1. All internal consistencies were acceptable with the exception of public negative feedback $(\alpha=.55)$, the results of which were thereby interpreted with caution. All items were assessed on a five-point Likert scale from 1 (not true at all) to 5 (completely true). All teaching practices exhibited considerable between-teacher variation but also substantial variance between different lessons of the same teacher $(\mathrm{ICC} 1=.27-.53, p<.05$; see Table 1$)$. Before returning the diaries, we also asked the teachers to state any special or noteworthy issues they might have encountered (e.g., forgetting to fill out the diary once). No problems with the diary were mentioned,
Table 1

Overview of the Scales Included in the Lesson Diary Assessing Teaching Practices

\begin{tabular}{|c|c|c|c|c|}
\hline Scale & $\#$ & $\alpha$ & ICC1 & Example item \\
\hline Interestingness & 6 & .77 & .53 & $\begin{array}{l}\text {... I used examples from everyday life to show the } \\
\text { students what German / Mathematics can be used } \\
\text { for. }\end{array}$ \\
\hline $\begin{array}{l}\text { Cognitive } \\
\text { stimulation }\end{array}$ & 4 & .67 & .37 & $\begin{array}{l}\text {... I had my students explain their thought } \\
\text { processes in detail. }\end{array}$ \\
\hline Individualization & 3 & .82 & .20 & $\begin{array}{l}\text {... I varied the tasks to suit students of different } \\
\text { abilities. }\end{array}$ \\
\hline $\begin{array}{l}\text { Public negative } \\
\text { feedback }\end{array}$ & 3 & .55 & .49 & $\begin{array}{l}\text {... I told students in front of the whole class when } \\
\text { they did badly. }\end{array}$ \\
\hline Autonomy support & 6 & .76 & .47 & $\begin{array}{l}\text {... I encouraged the students to work } \\
\text { independently. }\end{array}$ \\
\hline Structuring & 2 & .87 & .27 & $\begin{array}{l}\text {... I emphasized the relationships between the } \\
\text { topics covered. }\end{array}$ \\
\hline Collaboration & 4 & .93 & .23 & ... I encouraged students to work together. \\
\hline $\begin{array}{l}\text { Heterogeneous } \\
\text { grouping }\end{array}$ & 2 & .79 & .36 & $\begin{array}{l}\ldots \text { the students worked together with bad and good } \\
\text { students in each group. }\end{array}$ \\
\hline $\begin{array}{l}\text { Homogeneous } \\
\text { grouping }\end{array}$ & 2 & .78 & .38 & $\begin{array}{l}\text {... the better students worked with each other and } \\
\text { the worse students worked with each other. }\end{array}$ \\
\hline Competition & 5 & .79 & .49 & $\begin{array}{l}\text {... I encouraged my students to compete with each } \\
\text { other. }\end{array}$ \\
\hline
\end{tabular}

Note. \# denotes the number of items, $\alpha$ the internal consistency of the respective scale, and ICC1 represents the amount of variance on the level of the diaries that can be attributed to the individual teachers. All items were focused on the past lesson following the item stem "In my lesson today in German / Mathematics ...". We used "German" or "Mathematics" depending on which subject the teachers participated with. Presented are translations of example items. All items are presented in Table S1 in the supplementary materials. The actual diary itself is provided in Figure S2.

which we deem as evidence for the practicability of this assessment approach.

\subsection{Analyses}

Missing values due to item non-response occurred rarely (less than $4.5 \%$ for teachers' goals, and less than $3.7 \%$ for the diary entries - with the exception of items concerning grouping and individualization that were only to be answered to when the teachers had conducted group or partner work). The missing data was imputed using the EM-algorithm (Peugh \& Enders, 2004). We performed structural equation modelling using the lavaan package in $\mathrm{R}$ (Version 0.6-10, Rosseel et al., 2022). We conducted two-level analyses that modeled the differences in instructional practices between the different teachers. We regressed the ten aspects of instructional behaviors simultaneously on the four goals on Level 2. Next, we included gender and teaching experience as control variables into the model to investigate the robustness of our findings. We provide all data and code in an open repository (https://osf.io/4s7x9/). 
Table 2

Means, Standard Deviations, and Correlations with Confidence Intervals

\begin{tabular}{|c|c|c|c|c|c|c|c|c|}
\hline Variable & $M$ & $S D$ & 1 & 2 & 3 & 4 & 5 & 6 \\
\hline \multicolumn{9}{|c|}{ Baseline teacher assessments } \\
\hline 1. Learning & 4.31 & 0.42 & & & & & & \\
\hline 2. Performance approach & 1.99 & 0.82 & .08 & & & & & \\
\hline 3. Performance avoidance & 2.37 & 0.83 & .02 & $.42 * *$ & & & & \\
\hline 4. Work avoidance & 2.34 & 0.96 & $-.22 * *$ & -.03 & $.33 * *$ & & & \\
\hline 5. Gender $($ male $=0$, female $=1)$ & 0.53 & & .14 & $-.19 *$ & -.07 & .08 & & \\
\hline 6. Teaching experience (years) & 10.4 & 10.1 & -.08 & .07 & -.13 & $-.23 * *$ & $-.18 *$ & \\
\hline \multicolumn{9}{|c|}{ Diary assessments of teachers' instructional practices } \\
\hline Interestingness & 3.14 & 0.64 & $.28 * *$ & .09 & -.06 & -.05 & .07 & -.06 \\
\hline Cognitive stimulation & 3.38 & 0.62 & .17 & .08 & -.05 & -.11 & -.03 & $-.29 * *$ \\
\hline Individualization & 1.88 & 0.54 & .02 & .05 & .01 & -.01 & -.10 & $-.20 *$ \\
\hline Public negative feedback & 1.77 & 0.55 & -.04 & $.28 * *$ & $.38 * *$ & .08 & .05 & $-.20 *$ \\
\hline Autonomy support & 3.75 & 0.57 & $.24 * *$ & -.00 & -.15 & -.13 & .12 & -.16 \\
\hline Structuring & 3.79 & 0.70 & $.26 * *$ & $.24 * *$ & .06 & -.05 & -.13 & -.12 \\
\hline Collaboration & 3.33 & 0.77 & $.19 *$ & -.12 & -.16 & .02 & $.27 * *$ & $-.18 *$ \\
\hline Heterogeneous grouping & 3.39 & 0.60 & .15 & -.12 & $-.22 * *$ & -.09 & .07 & .02 \\
\hline Homogeneous grouping & 2.04 & 0.57 & -.07 & .01 & .13 & $.20 *$ & .07 & -.09 \\
\hline Competition & 1.62 & 0.51 & -.01 & $.34 * *$ & $.23 * *$ & $.22 * *$ & -.09 & -.06 \\
\hline
\end{tabular}

Note. $N=134$ teachers and $N=670$ daily assessments. Columns $1-6$ show bivariate correlations of teachers' goals and demographics with each other as well as with the instructional practices (averaged across the multiple lessons responded to by each teacher). $*: p<.05$, **: $p<.01$.

\section{Results}

\subsection{Descriptive Results}

Descriptively, the results (see Table 2) indicated strong learning goals and weak performance and work avoidance goals, and substantial differences between the different teachers (reflected in the standard deviations). We observed meaningful differences between teachers regarding how much they reported having used the different instructional behaviors across the survey time. There were only small differences in achievement goals based on gender and teaching experience (see supplementary materials), with women reporting fewer performance approach goals than men $(\beta=-.18, p=.035)$, and work avoidance goals decreasing with more teaching experience $(\beta=-.22, p=.003)$.

\subsection{Main Results: Linkages Between Achievement} Goals and Teaching Practices

Results of the path modeling (see Table 3 ) showed that learning goals (see Hypothesis 1) were positively linked with nearly all mastery-based instructional practices (apart from individualization) but not statistically significantly related to instructional practices characteristic of a performance climate (public negative feedback, homogeneous grouping, competition). This means that teachers who strongly aimed to improve their own competencies also reported a higher use of mastery-based teaching practices (and no differences in performance-based practices) in the teaching diary compared to teachers with weaker learning goals. Performance approach goals (see Hypothesis 2) were statistically significantly related to use of competition and structuring during the five weeks, but not to the other practices. As expected, performance avoidance goals (see Hypothesis 3) were negatively related to the use of autonomy support, collaboration, and heterogeneous grouping (which can each be regarded as masterybased teaching practices) and were positively related to the performance-based teaching practice of public negative feedback. Lastly, work avoidance goals (see Hypothesis 3 ) were positively related to the two performance-based teaching practices, homogenous grouping and competition, but did not portray statistically significant associations with the other aspects.

When including gender and teaching experience as control variables, these linkages remained largely robust apart from two effects: Performance approach goals reached statistical significance regarding public negative feedback - the third of the three considered 
Table 3

Associations Between Teachers' Achievement Goals and Instructional Practices

\begin{tabular}{|c|c|c|c|c|c|c|c|c|c|c|}
\hline & $\begin{array}{c}\text { Interesting- } \\
\text { ness }\end{array}$ & $\begin{array}{c}\text { Cognitive } \\
\text { stimulation }\end{array}$ & $\begin{array}{c}\text { Individual- } \\
\text { ization }\end{array}$ & $\begin{array}{l}\text { Public neg. } \\
\text { feedback }\end{array}$ & $\begin{array}{c}\text { Autonomy } \\
\text { support }\end{array}$ & Structuring & $\begin{array}{c}\text { Colla- } \\
\text { boration }\end{array}$ & $\begin{array}{l}\text { Heterog. } \\
\text { Grouping }\end{array}$ & $\begin{array}{l}\text { Homog. } \\
\text { Grouping }\end{array}$ & Competition \\
\hline \multicolumn{11}{|c|}{\begin{tabular}{|c|} 
\\
\end{tabular}} \\
\hline Learning & $.31(.09)$ & $.17(.10)$ & $.02(.12)$ & $-.07(.09)$ & $.26(.09)$ & $.31(.10)$ & $.30(.11)$ & $.19(.10)$ & $-.04(.10)$ & $.02(.09)$ \\
\hline Performance approach & $.14(.10)$ & $.12(.11)$ & $.07(.13)$ & $.15(.10)$ & $.05(.10)$ & $.31(.11)$ & $-.08(.12)$ & $-.06(.11)$ & $-.01(.11)$ & $.37(.09)$ \\
\hline Performance avoidance & $-.16(.11)$ & $-.10(.12)$ & $-.03(.14)$ & $.37(.10)$ & $-.18(.11)$ & $-.07(.12)$ & $-.23(.13)$ & $-.24(.11)$ & $.09(.12)$ & $.02(.10)$ \\
\hline Work avoidance & $.07(.10)$ & $-.05(.11)$ & $.01(.13)$ & $-.05(.10)$ & $-.03(.10)$ & $.04(.11)$ & $.17(.12)$ & $.01(.11)$ & $.20(.11)$ & $.26(.09)$ \\
\hline$R^{2}$ & .12 & .06 & .01 & .20 & .11 & .18 & .14 & .10 & .06 & .20 \\
\hline \multicolumn{11}{|c|}{ Model 2} \\
\hline Learning & $.30(.09)$ & $.14(.10)$ & $.01(.12)$ & $-.12(.09)$ & $.22(.09)$ & $.31(.10)$ & $.22(.11)$ & $.18(.10)$ & $-.06(.10)$ & $.02(.09)$ \\
\hline Performance approach & $.16(.10)$ & $.15(.11)$ & $.08(.13)$ & $.20(.10)$ & $.09(.10)$ & $.30(.11)$ & $-.01(.12)$ & $-.06(.11)$ & $.01(.11)$ & $.37(.09)$ \\
\hline Performance avoidance & $-.16(.11)$ & $-.14(.11)$ & $-.07(.14)$ & $.35(.10)$ & $-.20(.11)$ & $-.10(.12)$ & $-.24(.12)$ & $-.24(.11)$ & $.09(.12)$ & $.01(.10)$ \\
\hline Work avoidance & $.05(.10)$ & $-.12(.11)$ & $-.05(.13)$ & $-.10(.10)$ & $-.08(.10)$ & $.02(.11)$ & $.09(.12)$ & $.01(.11)$ & $.18(.11)$ & $.25(.10)$ \\
\hline Gender & $.04(.09)$ & $-.09(.10)$ & $-.17(.12)$ & $.10(.09)$ & $.08(.09)$ & $-.19(.10)$ & $.25(.11)$ & $.03(.10)$ & $.07(.10)$ & $-.06(.09)$ \\
\hline Teaching experience & $-.05(.09)$ & $-.40(.09)$ & $-.32(.11)$ & $-.20(.09)$ & $-.20(.09)$ & $-.19(.10)$ & $-.19(.11)$ & $.01(.10)$ & $-.05(.10)$ & $-.05(.09)$ \\
\hline$R^{2}$ & .12 & .20 & .11 & .25 & .15 & .24 & .24 & .10 & .07 & .21 \\
\hline
\end{tabular}

Note. $N=134$. Reported are standardized regression weights with their standard errors in brackets. Statistically significant coefficients $(p<.05)$ are boldfaced. Correlations between the dependent variables as well as residual correlations were modeled but are not presented for clarity.

performance-based teaching practices, and work avoidance goals were no longer statistically significantly related to homogeneous grouping. Descriptively both parameter estimates did not change substantially.

\section{Discussion}

That teachers' achievement goals also matter for their teaching practices is a central premise of teacher motivation research. In the present work, we addressed two key limitations of prior research regarding this premise by considering ten theoretically grounded teaching practices central to motivating lessons and using a standardized lesson diary approach for assessing them. Through multilevel analyses, our findings indicated that learning goals are linked with teachers' use of mastery-based teaching practices, while performance approach goals are linked with performancebased practices, and performance avoidance and work avoidance goals exhibited more nuanced links with specific practices. Gender and teaching experience did not substantially change the main results when controlled for. Taken together, this illuminates robust linkages between teachers' goals and specific teaching practices.

Specifically, the positive links between learning goals and nearly all mastery-based teaching practices (with the exception of individualization, and, controlling for teaching experience, cognitive stimulation) align very well with the hypothesized favorable orientations spanned up when pursuing such goals (Hypothesis 1). This complements past findings on linkages with self-reported trait use of general mastery-practices (e.g., Daniels, 2015; Retelsdorf et al., 2010; Shim et al., 2013; Wang et al., 2017) and students' reports thereof (e.g., Kalyar et al., 2018; Schiefele \& Schaffner, 2015), and extends these findings to a wide set of specific mastery-based practices (George \& Richardson, 2019; Han et al., 2015). This means that learning goals do not just lead to better teaching due to teachers with such orientations focusing on specific aspects of mastery-based teaching, but that these motivational differences are reflected broadly in many teaching practices. This clearly speaks for learning goals as an important premise for successful teaching. However, despite descriptively indicating such a pattern, our findings did not lend support to learning goals also going along with less performance-based practices (which has been observed in some studies, see Daumiller et al., 2022), implying that learning goals are primarily associated with masterybased practices. Thus, a clear takeaway for future research is that only considering learning goals would be shortsighted, but also other types of achievement goals 
need to be considered to comprehensively describe and predict how teachers differ in their teaching practices.

Performance approach goals being positively associated with public negative feedback and competition-two of the three performance-based practices that we considered-provides support for the expected detrimental links between performance approach goals and performance-based practices (Hypothesis 2). Similar to learning goals, this extends prior research on linkages between these goals with general performance-based practices (e.g., Mascret et al., 2017; Retelsdorf et al., 2010; Shim et al., 2013; Wang et al., 2017). Further, we found strong performance approach goals to go along with increased structuring of lessons. To interpret this unexpected finding, it is worth bearing in mind that performance goals were operationalized based on how important others (such as students, parents, or colleagues) perceived one's teaching - with which increased structure might be particularly helpful, as this is easily visible to others. In particular, structuring might help facilitate control over what is going on in the classroom, and, by extension, a higher likelihood of achieving a good impression (in line with the positive linkages reported for performance approach goals and a preference for teacher-focused teaching; see Yin et al., 2017). As such, this strengthens the notion that teachers' goals are not only associated with what teachers do in class due to the competence definitions and standards proffered by these goals, but also directly for achieving the goals themselves. Further, this extends prior research that certain mastery-based practices are also linked to performance goals (see Daumiller et al., 2022; Dresel et al., 2013). As such, the comprehensive consideration of specific teaching practices appears as an important direction for future research to better understand these effects and come to a more thorough understanding of how exactly achievement goals matter for what teachers do in the classroom. This is especially the case as other sources of assessments, such as students' perceptions, cannot usually track different aspects of teaching on such a differentiated level, and observer ratings do not readily capture variability across multiple lessons.

In contrast to learning and performance approach goals, findings for performance avoidance and work avoidance goals were more nuanced. Aligning with our expectations (Hypothesis 3), we found strong performance avoidance goals to be associated with more performance-based and less mastery-based teaching practices. This augments past research that - if at allfound linkages with performance-based practices but not also mastery-based practices (see overview by Daumiller et al., 2022). Descriptively, most of these effects pointed to a clear pattern, but only some were statistically significant, which might be a function of some effects being small and difficult to detect in our sample. Therefore, it appears logical that we found the clearest effects for the provision of autonomy support, heterogeneous grouping, and collaborative learning forms: these aspects might be more strongly linked to performance avoidance goals given that all three yield a high potential for creating unfamiliar situations-such as unexpected questions or group processes that might be threatening to teachers worried about not being able to handle situations well and appearing incompetent. We therefore consider it a valuable direction for future research to try to more precisely tap into how teachers perceive what is going on in the classroom in relation to their own motivation (e.g., coping strategies or worries inhibiting teachers from using certain teaching practices, see Salkovsky et al., 2015). Opposed to this, work avoidance goals emerged as less detrimental: contrary to our expectations, they were typically not significantly and only weakly associated with the teaching practices. This could also be due to our measures focusing on the use of teaching practices - but not so much the quality with which they were used. Some of the practices (such as autonomy support or facilitating collaboration among students) might also be realizable with strong work avoidance goals (e.g., through having students independently work on texts in small groups instead of preparing contents oneself). To follow up on this, we consider it an interesting perspective to investigate in more detail how exactly teachers employ teaching practices in class.

Finally, for gender and professional experience, we found few effects and relatively robust links between goals and teaching practices. While two effects were no longer statistically significant when controlling for gender and professional experience, their parameter estimates changed very little. This means that this might rather be a statistical power issue than a substantial effect. For future considerations of how goals matter, this implies that linkages between goals and teaching practices do not substantially appear to be a function of differences in gender and teaching experiences, strengthening the robustness of our findings.

From a more practical perspective, our findings speak to the usefulness of a standardized lesson diary to assess differences in teachers' teaching practices, extending first insights into the merits of such an approach for assessing teachers' emotions (Frenzel \& Götz, 2007; Goetz et al., 2015) to classroom actions 
(Martschinke \& Kammermeyer, 2003). Specifically, we encountered no problems with carrying out this approach (e.g., teachers not understanding or forgetting to fill out the diaries), while the findings regarding the measured scores (variances, associations) corroborated our theoretical expectations and indicated that such an approach allows for the assessment of differences between different teachers in their teaching that aligned well with past findings based on other self-reports or student-reports. While the diary approach provides multiple advantages - including a likely more accurate report of specific teaching practices given a timely presentation right after these lessons (see Schmitz \& Wiese, 2006) and better acceptance as well as increased ecological validity as opposed to more invasive approaches entailing videotaping or presence of external observers - it should be borne in mind that it is still a self-report tool that only taps into teachers' perspectives. Future research should therefore not neglect other means, such as reports by students or other observers to more holistically understand what is going on in the classroom. Besides it's purposes for research, such diaries can also be a helpful tool for teachers themselves to more systematically reflect on their lessons (complementary to external observations from e.g. colleagues, or students' perceptions; see Hattie, 2012; Lally \& Veleba, 2000; Schön, 1987). To this end, the standardized scales that we focused on regarding specific teaching behaviors relevant for motivating lessons can provide a helpful foundation to more systematically self-observe the lessons regarding this aspect. Such an approach can also be supplemented with further qualitative responses (e.g., open ended questions on "critical events"), as nearly every lesson provides room for surprises and unexpected situations. In addition, open questions can help to also inform about other goals relevant for the teachers. In the present work, we focused on achievement goals solely. Even though these goals have been found to be prevalent and relevant in research on teaching and teacher education, teachers are also driven by other types of goals (e.g., social goals; Butler, 2012; Ennis, 1994) which can also be gathered through a diary approach. However, both for research purposes as well as self-observation of teachers, the length of the diary should be kept in mind. While we did not find indications for teachers not filling out the diary immediately after the lessons in our study, diaries should be kept concise so that teachers can easily fill them out after/between lesson in order to allow for a broad applicability.

In terms of implications for teacher professionalization, our results especially emphasize the relevance of learning goals. Programs focused on fostering adaptive goals of teachers and reducing maladaptive motivations, should therefore focus on enhancing learning goals while reducing strong avoidance goals (e.g., by addressing performance concerns or developing other strategies to deal with high work load). This is especially the case for teacher education, which, by extension, would profit from consistently accentuating learning goals in the aspiring teachers (see Morgan \& Kingston, 2008). Further, for interventions seeking to support instructional practices, our findings emphasize that addressing teachers' goals can a be worthwhile approach. Besides directly addressing their goals in further training (where the relevance of different goals can be discussed, and teachers can learn strategies to monitor and change their goal pursuit), teachers' goal pursuit can be enhanced indirectly through supporting these goal striving processes by an arrangement of contextual features such as the goal structures and emphases within the teachers' school environment (Dickhäuser et al., 2021; Lüftenegger et al., 2014).

When interpretating our findings, there are some additional limitations to be borne in mind that also provide relevant implications for future research. First, our sample was characterized by rather favorable motivation already (strong learning goals and weak work avoidance goals), which is typical for research on teachers' achievement goals (see e.g., Butler, 2007, 2012; Nitsche et al., 2013a; Pamuk et al., 2017) but might limit the effects that we can observe for the goals. At the same time, teachers who are more confident about or interested in their teaching might have been more prone to participate in the study than those with weaker teaching confidence or interest. As such, our sample likely does not represent a representative crosssection of teachers with regard to their motivation and teaching practices. This is rather a general limitation of research on teacher motivation and limits the interpretability of the mean levels that we observed but should not affect the relationships that we found (as these are based on interindividual differences) and suggests the importance of identifying ways to reach teachers who may be less motivated or interested. Relatedly, while our sample size was average for diary studies and investigations into effects of teachers' goals on teaching practices (see Daumiller et al., 2022, for an overview), it might not have been large enough to also detect small effects (e.g., of performance avoidance goals), necessitating future research with broader and larger samples on this topic. Second, even though we assessed achievement goals before the teachers reported their specific teaching practices, also reciprocal effects are 
possible given that both achievement goals and teaching practices are partly temporally stable. Specifically, emphasizing mastery or performance in the classroom might also affect the kinds of success or competences teachers consider most valuable not only for their students, but also for themselves. Relatedly, it cannot be ruled out that the mere use of diaries itself might influence teaching practices, possibly leading to teachers using more desirable practices or practices more in line with their previous replies (however, generally, there is little indication that diary studies cause behavior change; see Newcomb et al., 2018).

\subsection{Conclusion}

Taken together, our findings clearly point to the high relevance of learning goals for motivating teaching practices and illustrate the merits of a diary approach to study the different behaviors that goals elicit. Especially for avoidance-based goals, this might be very helpful to gather a more complete understanding of how goals matter for motivational dynamics in class and ultimately different student outcomes.

\section{References}

Ames, C., \& Ames, R. (1984). Goal structures and motivation. The Elementary School Journal, 85(1), 39-52. https://doi.org/10.1086/461390

Ames, C. (1992). Achievement goals and the classroom motivational climate. In J. L. Meece \& D. H. Schunk (Eds.), Student perceptions in the classroom (pp. 327-348). Erlbaum.

Baumert, J., Blum, W., Brunner, M., Dubberke, T., Jordan, A., Klusmann, U., ... Tsai, Y. M. (2008). Professionswissen von Lehrkräften, kognitiv aktivierender Mathematikunterricht und die Entwicklung von mathematischer Kompetenz (COACTIV) [Professional knowledge of teachers, cognitive activating mathematic classes and the developement of mathematical competences (COACTIV)]. Max-Planck-Institut für Bildungsforschung.

Benita, M., Roth, G., \& Deci, E. L. (2014). When are mastery goals more adaptive. Journal of Educational Psychology, 106(1), 258-267. https://doi.org/10.1037/a0034007

Benning, K., Daumiller, M., Praetorius, A.K., Lenske, G., Dickhäsuer O., \& Dresel, M. (2019). Evaluation eines Interventionsansatzes zur Verbesserung von Motivation und motivationsförderlichem Unterrichtshandeln von Lehrkräften auf Basis der Zielorientierungstheorie [Evaluation of an intervention approach to improve goal orientations and instructional practices of teachers based on achievement goal theory]. Unterrichtswissenschaft, 47, 313-335. https://doi.org/10.1007/s42010-018-0025-9

Black, A. E., \& Deci, E. L. (2000). The effects of instructors' autonomy support and students' autonomous motivation on learning organic chemistry. Science Education, 84, 740-756. https://doi.org/10/brq8jq

Butler, R. (2007). Teachers' achievement goal orientation and association with teachers' help-seeking. Journal of Educational Psychology, 99, 241-252. https://doi.org/10.1037/00220663.99.2.241

Butler, R. (2012). Striving to connect. Journal of Educational Psychology, 104, 726-742. https://doi.org/10.1037/a0028613
Butler, R., \& Shibaz, L. (2008). Achievement goals for teaching as predictors of students' perceptions of instructional practices and students' help seeking and cheating. Learning and Instruction, 18, 453-467. https://doi.org/10.1016/j.learninstruc.2008.06.004

Butler, R., \& Shibaz, L. (2014). Striving to connect and striving to learn. International Journal of Educational Research, 65, 4153. https://doi.org/10.1016/j.ijer.2013.09.006

Cho, Y., \& Shim, S. S. (2013). Predicting teachers' achievement goals for teaching. Teaching and Teacher Education, 32, 1221. https://doi.org/10.1016/j.tate.2012.12.003

Daniels, L. M. (2015). From pre-service to practicing teacher. $E d$ ucational Psychology, 35, 984-1005. https://doi.org/10.1080/01443410.2013.870329

Daniels, L. M., Frenzel, A. C., Stupnisky, R. H., Stewart, T. L., \& Perry, R. P. (2013). Personal goals as predictors of intended classroom goals. British Journal of Educational Psychology, 83, 396-413. https://doi.org/10.1111/j.20448279.2012.02069.x

Daumiller, M., Grassinger, R., Dickhäuser, O., \& Dresel, M. (2016). Structure and relationships of university instructors' achievement goals. Frontiers in Psychology, 7, 1-14. https://doi.org/10.3389/fpsyg.2016.00375

Daumiller, M., Dickhäuser, O. \& Dresel, M. (2019). University instructors' achievement goals for teaching, Journal of Educational Psychology, 111, 131-148. https://doi.org/10.1037/edu0000271

Daumiller, M., Faching, M. S., Steuer, G., Dickhäuser, O., \& Dresel, M. (2022). From teachers' personal achievement goals to students' perceptions of classroom goal structures. Teaching and Teacher Education, 111. Advanced online publication. https://doi.org/10.1037/10.1016/j.tate.2021.103617

Daumiller, M., Janke, S., Rinas, R., Hein, J., Dickhäuser, O., \& Dresel, M. (2023). Different time and context $=$ different goals and emotions? Temporal variability and context specificity of achievement goals for teaching and associations with discrete emotions. Contemporary Educational Psychology. Advanced online publication. https://doi.org/10.1016/j.cedpsych.2022.102139.

Daumiller, M., Rinas, R., Olden, D. \& Dresel, M. (2021). Academics' motivations in professional training courses. International Journal for Academic Development, 26(1), 7-23. https://doi.org/10.1080/1360144X.2020.1768396

Ditton, H. (2010). QuaSSU - QualitätsSicherung in Schule und Unterricht [QuaSSU - Quality Assurance in schools and lessons]. Retrieved from: http://www.quassu.net/seite4.htm

Dresel, M., Martschinke, S., \& Kopp, B. (2009, April). Elementary school teachers' feedback practices, perceived classroom goal structures, and students' personal achievement goals. Paper presented at the 90th Annual Meeting of the American Educational Research Association (AERA) in San Diego.

Dweck, C. S. (1984). Motivation. In R. Glaser \& A. Lesgold (Eds.), The handbook of psychology and education (pp. 87136). Lawrence Erlbaum.

Ennis, C. D. (1994). Urban secondary teachers' value orientations: Social goals for teaching. Teaching and Teacher Education, 10(1), 109-120. https://doi.org/10.1016/0742-051X(94)900442

Elliot, A. J. \& Hulleman, C. S. (2017). Achievement Goals. In A. J. Elliot, C. S. Dweck \& D. S. Yeager (Eds.), Handbook of competence and motivation (2nd ed., 43-60). Guilford. 
Frenzel, A. C. \& Götz, T. (2007). Emotionales Erleben von Lehrkräften beim Unterrichten. Zeitschrift für Pädagogische Psychologie, 21, 283-295. https://doi.org/10.1024/1010R0652.21.3.283

Frey, A., Taskinen, P., Schütte, K., Prenzel, M., Artelt, C., Baumert, J. et al. (2009). PISA 2006 Skalenhandbuch. Waxmann.

George, S. V., \& Richardson, P. W. (2019). Teachers' goal orientations as predictors of their self-reported classroom behaviours. International Journal of Educational Research, 98, 345-355. https://doi.org/10.1016/j.ijer.2019.09.011

Goetz, T., Becker, E. S., Bieg, M., Keller, M. M., Frenzel, A. C. \& Hall, N. C. (2015). The glass half empty. PLoS One, 10, e0137441. https://doi.org/10.1371/journal.pone.0137441

Gorozidis, G., \& Papaioannou, A. G. (2014). Teachers' motivation to participate in training and to implement innovations. Teaching and Teacher Education, 39, 1-11. https://doi.org/10.1016/j.tate.2013.12.001

Han, J., \& Yin, H. (2016). Teacher motivation: Definition, research development and implications for teachers. Cogent Education, 3(1), 1217819. https://doi.org/10.1080/2331186X.2016.1217819

Han, J., Yin, H., \& Wang, W. (2015). Exploring the relationship between goal orientations for teaching of tertiary teachers and their teaching approaches in China. Asia Pacific Education Review, 16, 537-547. https://doi.org/10.1007/s12564-0159392-7

Hattie, J. A. C. (2012). Visible learning for teachers. Maximizing impact on learning. Routledge.

Helmke, A., Helmke, T., Schrader, F.RW. \& Wagner, W. (2007). Der Schüler Kurzfragebogen der DESI Videostudie [The student short questionnaire of the DESI video study]. University Koblenz Landau.

Jang, H. R. (2019). Teachers' intrinsic vs. extrinsic instructional goals predict their classroom motivating styles. Learning and Instruction, 60, 286-300. https://doi.org/10.1016/j.learninstruc.2017.11.001

Janke, S., Bardach, L., Oczlon, S., \& Lüftenegger, M. (2019). Enhancing feasibility when measuring teachers' motivation. Teaching and Teacher Education, 83, 1-11. https://doi.org/10.1016/j.tate.2019.04.003

Janke, S., Daumiller, M., Praetorius, A., Dresel, M., \& Dickhäuser, O. (2022). What reduces the adverse development of motivation at the beginning of secondary education. Zeitschrift für Erziehungswissenschaft. https://doi.org/10.1007/978-3- 658-31064-6_7.

Kalyar, M. N., Ahmad, B., \& Kalyar, H. (2018). Does teacher motivation lead to student motivation. Voprosy Obrazovaniya, 3, 91-119. https://doi.org/10.17323/1814-9545-2018-3-91-119

Kunter, M., \& Baumert, J. (2006). Who is the expert. Learning Environments Research, 9, 231-251. https://doi.org/10.1007/s10984-006-9015-7

Kunter, M., Baumert, J., Blum, W., Klusmann, U., Krauss, S., \& Neubrand, M. (Eds.). (2013). Cognitive activation in the mathematics classroom and professional competence of teachers. Springer Science \& Business Media.

Kunter, M., Baumert, J., \& Köller, O. (2007). Effective classroom management and the development of subject-related interest. Learning and Instruction, 17(5), 494-509. https://doi.org/10.1016/j.learninstruc.2007.09.002

Lally, C. G., \& Veleba, K. (2000). Language teacher observation and reflective diaries: An alternate perspective. Education, 12l(1), 106-114
Lauermann, F., \& Butler, R. (2021). The elusive links between teachers' teaching-related emotions, motivations, and self-regulation and students' educational outcomes. Educational Psychologist, 56(4), 243-249.

https://doi.org/10.1080/00461520.2021.1991800

Lüftenegger, M., Van De Schoot, R., Schober, B., Finsterwald, M., $\&$ Spiel, C. (2014). Promotion of students' mastery goal orientations. Educational Psychology, 34, 451-469. https://doi.org/10.1080/01443410.2013.814189

Lüftenegger, M., Tran, U., \& Bardach, L., Schober, B., \& Spiel, C. (2017). Measuring a classroom mastery goal structure using the TARGET dimensions. Zeitschrift für Psychologie, 224, 64-75. https://doi.org/10.1027/2151-2604/a000277

Mansfield, C. F., \& Beltman, S. (2014). Teacher motivation from a goal content perspective: Beginning teachers' goals for teaching. International Journal of Educational Research, 65, 54-64. https://doi.org/10.1016/j.ijer.2013.09.010

Mascret, N., Elliot, A. J., \& Cury, F. (2017). The 3x2 Achievement Goal Questionnaire for Teachers. Educational Psychology, 37, 346-361. https://doi.org/10.1080/01443410.2015.1096324

Martschinke, S. \& Kammermeyer, G. (2003). Jedes Kind ist anders [Every child is different]. Zeitschrift für Erziehungswissenschaft, 2, 257-275.

Midgley, C., Maehr, M. L., Hruda, L. Z., Anderman, E. M., Anderman, L. H., Freeman, K. E., ... Urdan, T. (2000). Manual for the Patterns of Adaptive Learning Scales (PALS). University of Michigan.

Morgan, K., \& Kingston, K. (2008). Development of a self-observation mastery intervention programme for teacher education. Physical Education \& Sport Pedagogy, 13(2), 109-129. https://doi.org/10.1080/17408980701345634

Newcomb, M. E., Swann, G., Mohr, D., \& Mustanski, B. (2018). Do diary studies cause behavior change. AIDS Behavior, 22, 2284-2295. https://doi.org/10.1007/s10461-018-20273

Nicholls, J. G. (1984). Achievement motivation: Conceptions of ability, subjective experience, task choice, and performance. Psychological Review, 91, 328-346. https://doi.org/10.1037//0033-295x.91.3.328.

Nicholls, J. G., Cheung, P. C., Lauer, J., \& Patashnick, M. (1989). Individual differences in academic motivation. Learning and Individual Differences, 1(1), 63-84. https://doi.org/10.1016/1041-6080(89)90010-1

Niikko, A., \& Ugaste, A. (2012). Conceptions of Finnish and Estonian pre-school teachers' goals in their pedagogical work. Scandinavian Journal of Educational Research, 56(5), 481495. https://doi.org/10.1080/00313831.2011.599424

Nitsche, S., Dickhäuser, O., Fasching, M. S., \& Dresel, M. (2011). Rethinking teachers' goal orientations. Learning and Instruction, 21, 574-586. https://doi.org/10.1016/j.learninstruc.2010.12.001

Nitsche, S., Dickhäuser, O., Fasching, M. S., \& Dresel, M. (2013a). Teachers' professional goal orientations. Learning and Individual Differences, 23, 272-278. https://doi.org/10.1016/j.lindif.2012.07.017

Nitsche, S., Dickhäuser, O., Fasching, M. S., \& Dresel, M. (2013b). Zielorientierungen von Lehrkräften als Prädiktoren lernrelevanten Verhaltens [Teachers goal orientations as predictors of vocational learning behavior]. German Journal of Educational Psychology, 27, 95-103. https://doi.org/10.1024/1010-0652/a000092

Pamuk, S., Sungur, S., \& Oztekin, C. (2017). A multilevel analysis of students' science achievements in relation to their self- 
regulation, epistemological beliefs, learning environment perceptions, and teachers' personal characteristics. International Journal of Science and Mathematics Education, 15(8), 14231440. https://doi.org/10.1007/s10763-016-9761-7

Papaioannou, A., \& Christodoulidis, T. (2007). A measure of teachers' achievement goals. Educational Psychology, 27(3), 349-361. https://doi.org/10.1080/01443410601104148

Patrick, H., Kaplan, A., \& Ryan, A. M. (2011). Positive classroom motivational environments. Journal of Educational Psychology, 103, 367-382. https://doi:10.1037/a002331

Pintrich, P. R. (2000a). Multiple goals, multiple pathways: The role of goal orientation in learning and achievement. Journal of Educational Psychology, 92(3), 544-555. https://doi.org/10.1037/0022-0663.92.3.544

Pintrich, P. R. (2000b). An achievement goal theory perspective on issues in motivation terminology, theory, and research. Contemporary Educational Psychology, 25, 92-104. https://doi.org/10.1006/ceps.1999.1017

Podsakoff, P. M., MacKenzie, S. B., Lee, J.-Y., \& Podsakoff, N. P. (2003). Common method biases in behavioral research. Journal of Applied Psychology, 88, 879-903. https://doi.org/10.1037/0021-9010.88.5.879

Praetorius, A. K., Grünkorn, J., \& Klieme, E. (2020). Towards developing a theory of generic teaching quality. Zeitschrift für Pädagogik, 66(1), 15-36. https://doi.org/10.3262/ZPB2001015

Praetorius, A.-K., Nitsche, S., Janke, S., Dickhäuser, O., Drexler, K., Fasching, M., \& Dresel, M. (2014). Here today, gone tomorrow? Revisiting the stability of teachers' achievement goals. Contemporary Educational Psychology, 39(4), 379387. https://doi.org/10.1016/j.cedpsych.2014.10.002

Praetorius, A. K., Pauli, C., Reusser, K., Rakoczy, K., \& Klieme, E. (2014). One lesson is all you need. Learning and Instruction, 31, 2-12. https://doi.org/10.1016/j.learninstruc.2013.12.002

Rakoczy, K. (2005). Motivationsunterstützung im Mathematikunterricht [Motivational support in teaching mathematics]. Zeitschrift für Pädagogik, 52(6), 822-843. https://doi.org 10.25656/01:4490

Ramm, G., Prenzel, M., Baumert, J., Blum, W., Lehmann, R., Leutner, D., ... Schiefele, U. (2006). PISA 2003 - Dokumentation der Erhebungsinstrumente [PISA 2003 - Documentation of the measuring instruments]. Waxmann.

Rausch, A. (2014). Using diaries in research on work and learning. In C. Harteis, A. Rausch, \& J. Seifried (Eds.). Discourses on professional learning (pp. 341-366). Springer.
Retelsdorf, J., Butler, R., Streblow, L., \& Schiefele, U. (2010). Teachers' goal orientations for teaching. Learning and Instruction, 20, 34-43. https://doi.org/10.1016/j.learninstruc.2009.01.001

Retelsdorf, J. \& Günther, C. (2011). Achievement goals for teaching and teachers' reference norms. Teaching and Teacher Education, 27, 1111-1119. https://doi.org/10.1016/j.tate.2011.05.007

Ross, C. M., \& Harrison, P. L. (2006). Ability Grouping. In G. G. Bear, \& K. M. Minke (Eds.), Children's needs III (pp. 579-588). National Association of School Psychologists.

Rosseel, Y. (2022). Lavaan. https://cran.r-project.org/web/packages/lavaan/index.html

Runhaar, P., Sanders, K., \& Yang, H. (2010). Stimulating teachers' reflection and feedback asking. Teaching and Teacher Education, 26, 1154-1161. https://doi.org/10.1016/j.tate.2010.02.011

Salkovsky, M., \& Romi, S. (2015). Teachers' coping styles and factors inhibiting teachers' preferred classroom management practice. Teaching and Teacher Education, 48, 56-65. https://doi.org/10.1016/j.tate.2015.01.016

Schiefele, U., \& Schaffner, E. (2015). Teacher interests, mastery goals, and self-efficacy as predictors of instructional practices and student motivation. Contemporary Educational Psychology, 42, 159-171. https://doi.org/1 10.1016/j.cedpsych.2015.06.005

Schön, D. A. (1987). Educating the reflective practitioner: Toward a new design for teaching and learning in the professions. Jossey-Bass.

Schutz, P. A., Crowder, K. C., \& White, V. E. (2001). The development of a goal to become a teacher. Journal of Educational Psychology, 93(2), 299-308. https://doi.org/10.1037/00220663.93.2.299

Shim, S. S., Cho, Y., \& Cassady, J. (2013). Goal structures. The Journal of Experimental Education, 81, 84-104. https://doi.org/10.1080/00220973.2011.635168

Skaalvik, E. M., \& Skaalvik, S. (2017). Motivated for teaching? Teaching and Teacher Education, 67, 152-160. https://doi.org/10.1016/j.tate.2017.06.006

Trull, T. J., \& Ebner-Priemer, U. (2013). Ambulatory assessment. Annual Review of Clinical Psychology, 9(1), 151-176. https://doi.org/10.1146/annurev-clinpsy-050212-185510

Wang, H., Hall, N. C., Goetz, T., \& Frenzel, A. C. (2017). Teachers' goal orientations. British Journal of Educational Psychology, 87, 90-107. https://doi.org/10.1111/bjep.12137 